\title{
Evaluating the performance of Andrographis paniculata leaves extract as additive for corrosion protection of stainless steel $316 \mathrm{~L}$ in seawater
}

\author{
W.M.K.W.M. Ikhmal, ${ }^{1,4}$ M.Y.N. Yasmin, ${ }^{2}$ M.F.F. Maria, ${ }^{1,4}$ \\ S.M. Syaizwadi, ${ }^{1,4}$ W.A.W. Rafizah, ${ }^{2,3}$ M.G.M. Sabri ${ }^{1,3,4} *$ and B.M. Zahid ${ }^{4} *$ \\ ${ }^{1}$ Advanced Nano Materials (ANoMa) Research Group, Universiti Malaysia Terengganu, \\ 21030 Kuala Nerus, Terengganu, Malaysia \\ ${ }^{2}$ Faculty of Ocean Engineering Technology and Informatics, Universiti Malaysia \\ Terengganu, 21030 Kuala Nerus, Terengganu, Malaysia \\ ${ }^{3}$ Materials Synthesis \& Characterization Laboratory (MSCL), Institute of Advanced \\ Technology, Universiti Putra Malaysia, 43400 UPM Serdang, Selangor, Malaysia \\ ${ }^{4}$ Faculty of Science and Marine Environment, Universiti Malaysia Terengganu, 21030 \\ Kuala Nerus, Terengganu, Malaysia \\ *E-mail: $\underline{\text { mohdsabri@umt.edu.my }}$
}

\begin{abstract}
Anti-corrosion protection coating serves as an effective way for the reduction of corrosion progress in a corrosive environment. With the increase of interest in green corrosion protection nowadays, Kalmegh or Andrographis paniculata from the family of Acanthaceae is evaluated for its potential as an additive in coating for stainless steel grade 316L (SS316L) via electrochemical impedance spectroscopy (EIS), potentiodynamic polarization (PP) and scanning electron microscope (SEM) in seawater. Characterization via Fourier transform infrared (FTIR) spectroscopy, Ultraviolet-Visible (UV-Vis) spectroscopy and High Performance Liquid Chromatography (HPLC) revealed the presence of asymmetry $-\mathrm{NH},-\mathrm{CH}$ and $-\mathrm{OH}$, two peaks at $450 \mathrm{~nm}$ and $661 \mathrm{~nm}$ as well as the identification of andrographolide with a retention time of $4.650 \mathrm{~min}$. Results showed an increase in corrosion resistance as the extract concentration in the coating increase. However, the efficiency was found to be limited at $10 \%$ extract concentration, and further increase diminished its inhibitive effect. Base on electrochemical analysis, coatings with the additive exhibited a mixed-type inhibitive property which was identified through the polarization curve. SEM micrograph of the coated steel surface showed inhomogeneous layers with rough structure possibly due to an aggressive attack of corrosive species in the medium on multiple sites.
\end{abstract}

Keywords: paint coating, Andrographis paniculata, marine, stainless steel, EIS. 


\section{Introduction}

Corrosion is a naturally occurring problem which results from the reaction of the material with its surrounding environment. The reactions generally involve the mechanism of ion reduction and oxidation at several sites on the surface of the steel [1]. Metal equipment without an effective corrosion precaution measure may get rusted even as it is exposed to the air. Thus, it can be understood that corrosion can take place almost in any environment at any given time. Corrosion study is an essential field since it impacts not only on structural failure but also concern the safety of life [2]. The losses resulting from corrosion are much more evident in the marine industry because of the environment promotes the reaction to occur faster. Marine-related industries in the past several years have provided a massive economic fund to counter the problem through the maintenance and preventive method [3,4]. To prevent a further catastrophic event from taking place, appropriate corrosion prevention is essential to be introduced in the industries as a means to reduce the potential of harmful effects originate from corrosion [5].

In the last few decades, a variety of methods and techniques are introduced to counter this issue. Among these preventive steps, the use of a corrosion inhibitor is the most widely accepted since it capable of reducing the rate of corrosion to an acceptable level [6]. The actions of the corrosion inhibitor are generally by adsorption of molecules on the metal surface, reducing the anodic and/or cathodic reaction and diminishing the rate of diffusion of corrosive species [7]. Recent discovery also suggests a new approach on what is called as "active-passive" which identified the coating as layers of barriers that protect the metal surface from the penetration of corrosive species (passive). On a different side, the active approach permits the barrier formation which will hinder redox reactions. This leads to the development of a Schottky barrier at the interface inducing electrons depletion [8]. Corrosion inhibitors are mostly identified by the presence of heteroatoms such as oxygen, nitrogen, and phosphorus having high basicity and electron density [9]. For a particular environment with a specific condition, several factors such as the type of metal, the range of alkalinity or acidity need to be taken as a major consideration to optimize the cost, availability, and safety [10]. Since the 1930s, numerous natural corrosion inhibitor has been tested for their potential use in this field in the wide range of application [11]. The growing interest in green inhibitor from natural resources arose decades ago when the common inhibitors used at that time was discovered to cause harmful effects on the environment due to its hazardous property [12]. Examples of these harmful inhibitors are phosphate and chromates. Additionally, corrosion inhibitor is not suitable for open system application such as in a marine environment. Thus, its deployment in the application of coating for means of corrosion protection as an additive is found to be much more flexible and a unique topic to cover.

Natural plant resources are prioritized due to its suitability with nature having the properties of non-hazard, bio-degradable and readily available in a large quantity [13]. It was also reported that the extract of different plant materials possesses dissimilar organic 
compound which suggests that different plants have different potential in its capability to inhibit corrosion [14]. Kalmegh or also known as the "king of bitters" are categorized in the family Acanthaceae can be largely found in the region of tropical and subtropical Asia $[15,16]$. Growing in relatively high moistures and shady places, the extent of its height can reach up to $110 \mathrm{~cm}$. With the characteristics of dark green slender stem and hairless lanceshaped leaves, this plant also bears fruits in the shape of a small capsule [17]. Several studies showed the anti-oxidant effect of Kalmegh aqueous extract originates from its capability to activate the antioxidant enzymes which induce the oxidants reaction [18]. The primary constituent of Kalmegh leaves extracts consists of a bicyclic diterpenoid lactone known as andrographolide. Some identifications of the functional groups were hydroxyl $(\mathrm{O}-\mathrm{H})$, amines $\left(-\mathrm{NH}_{2}\right)$, alkenes $(\mathrm{C}=\mathrm{C})$ and more [19]. A study performed using Kalmegh leaves extract (KLE) as an inhibitor in the $\mathrm{NaOH}$ solution showed that the extract increased the inhibition efficiency up to $82.24 \%$ and $82.45 \%$ for both analysis of EIS and PP. Moreover, KLE was also found out to be a mixed type inhibition with a dominant cathodic effect [20]. As a component in a coating, a research suggested that the incorporation of KLE as an additive yields a significant increase in coating performance when it is used up to $6 \mathrm{wt} . \%$, and further addition caused a significant drop in the barrier quality [21].

Application of coating on metal equipment and structural construction is widely employed and used in various fields. Anti-corrosion coating which incorporates natural products as to enhance its efficiency and ability has been extensively studied. Some other examples of the studies that incorporated plant extracts include lawsone, hibiscus, olive leaves and roselle [22-25]. The anti-corrosive coating can ensure the metal it is coated with have a longer life expectancy and thus reducing a lot of costs mainly for maintenance. Generally, there are four constituents that required major considerations when constructing a new type of coating which is binder, pigment, solvent, and additive [26]. Through the understanding of the basis of the environment and material, these four components are carefully selected to ensure it is suitable for the specific application. Binder is regarded as the component which holds the coating together and gives the coating its adhesion property. Adhesion is the process of coating sticking or attaching itself to the surface of the material, and a high-quality binder generally provides an excellent adhesion property to the coating as a whole. Through the addition of a binder, the characteristic of the coating such as cohesive strength and durability is determined. Pigment imparts the coating its color while sometimes providing a new advantageous property to enhance the coating performance. Such examples are by adding a material with lower electrode potential that served as a sacrificial layer to retard corrosion from occurring on the protected surface of the substrate. Next, the solvent is used to control the viscosity as well as for the thinning and the cleanup process. Finally, the additive is a chemical substance that is usually added to introduce a new major property to the coating. Although it is added in a small quantity, the additive is typically capable of affecting specific vital properties such as shelf life and 
curing. By optimizing the materials selected, a better and highly capable coating for specific applications can be created.

Specimens for the corrosion study through immersion test used are SS316L which is classified as austenitic stainless steel containing molybdenum [27]. The capital L indicates that the steel contains lower carbon than the typical type of 316. This type of stainless steel has higher resistance in many aggressive or corrosive environments. Furthermore, 316L also capable of resisting the deaerated and in $\mathrm{H}_{2} \mathrm{~S}$ containing condition [28]. Having an addition of $2.5 \%$ of molybdenum, the applications of SS316L covers wide areas including its usage as pump shafts, valves parts, marine fitting, fastener, pulp machinery, and petrol chemical equipment. Albeit its usage in marine-related field is widely accepted since the last several years, SS316L is actually sensitive to a chlorinated medium such as seawater. When immersed in this condition, the steel will be subjected to severe and accelerated corrosion problems such as pitting and crevice corrosion. Furthermore, this event will also risk the exposure of chromium to the aquatic life; a well-known dangerous substance which can increase the mortality rate of the dish. Thus, as to prevent further wasting and any unwanted occurrence, the study aims at improving the steel ability in its usage in such environment by employing coating that has been enhanced with the plant extract of Andrographis paniculata.

\section{Materials and Methods}

\subsection{Chemicals}

$80 \%$ ethanol, acetone, acetonitrile and distilled water were supplied by the Central Lab of Universiti Malaysia Terengganu. KTH 1K Alkyd and general thinner were purchased from local Nippon Paint Holdings Co., Ltd. and seawater was collected from Setiu, Terengganu.

\subsection{Preparation of extract}

The extraction process was carried by immersing $30 \mathrm{~g}$ of Kalmegh powder in $600 \mathrm{ml}$ of ethanol for 48 hours. The macerated sample was collected and filtered using filter paper. The extract later was concentrated by using rotary evaporator and stored in the refrigerator until further used.

\subsection{Determination of Kalmegh (Andrographis paniculata) functional group}

Characterization through the spectroscopy of FTIR is used to determine the active functional groups present in the extract. By using the IR radiation frequencies that pass through the extract, the functional groups are identified since each absorbs different characteristic of IR. FTIR Spectroscopy was carried out using Thermo Nicolet Avatar 380. A small quantity of diluted extract was directly deposited onto the sample disk, creating a thin film. A spectrum was scanned in the frequency range of infrared light ranging from 4000 to $700 \mathrm{~cm}^{-1}$. 


\subsection{Ultraviolet-Visible spectroscopy}

Ultraviolet-visible (UV-Vis) spectroscopy is used to measure the amount of light absorbed at a particular wavelength as the light passes through a sample or substances. Absorption might be exhibited as transmittance $\left(T=I / I_{0}\right)$ or absorbance $\left(A=\log I_{0} / I\right)$. If no absorption occurred, $T=1.0$ and $A=0$. Most spectrometers show absorbance on the vertical axis, and the observed range is from 0 (100\% transmittance) to 2 (1\% transmittance). The wavelength of maximum absorbance is a characteristic value, designated as $\lambda_{\max }$. Different compounds may have very different absorption maxima and absorbance.

\subsection{High Performance Liquid Chromatography}

High performance liquid chromatography-Prominence (Shimadzu) with Phenomenex Luna $5 \mu \mathrm{m} \mathrm{C} 18100 \mathrm{~A}(250 \mathrm{~mm} \times 4.6 \mathrm{~mm}, 5 \mu \mathrm{m})$ column equipped with photometric diode array (PDA) were used to determine the presence of andrographolide compound in the leaves extract of Kalmegh. The optimization of chromatographic performance on mobile phase and wavelength were first considered to get better peak area response. The mobile phases with composition of $20 \%$ water (A) and $80 \%$ acetonitrile (B) were used in determining the compound with higher signal intensity and symmetry. The wavelength used was $225 \mathrm{~nm}$ with flow rate of $1.0 \mathrm{ml} / \mathrm{min}, 10 \mathrm{mins}$ of running time and pressure of $\leq 7.0 \mathrm{MPa}$. The injection volume used was $20 \mu \mathrm{l}$ and the column temperature was set to $30.5^{\circ} \mathrm{C}$. The sample was tested a minimum three times to validate the precision of the data.

\subsection{Preparation of substrate}

The specimen used for the experimental test is the $316 \mathrm{~L}$ grade stainless steel. The specimens were cut into $25 \mathrm{~mm} \times 25 \mathrm{~mm} \times 15 \mathrm{~mm}$ according to ASTM E3-11. For the removal of an unwanted layer, the substrate was polished using 320-grit silicon carbide paper. The routine cleaning process was carried out using deionized water followed by acetone, air-dried and were used without any further storage.

\subsection{Preparation of paint formulation}

For the preparation of coating, several components are mixed up according to Table 1 below. The paint selected is KTH $1 \mathrm{~K}$ Alkyd due to the previous study showed it is suitable and workable for the incorporation of natural plant extract although the paint itself is actually made for the application on mild steel. General thinner is chosen since it is readily available and possesses similar criteria for the formulation in the previous research [29]. Three types of coating are produced based on different Kalmegh extract concentration as and the volume of extract solution was calculated based on Equation 1:

$$
\frac{\text { Volume of Solution }(\mathrm{ml})}{\text { Volume of Solvent }(\mathrm{ml})} \times 100
$$


Table 1. Coating formulation.

\begin{tabular}{cccc}
\hline Coating & Paint $(\mathbf{m l})$ & Extract $(\%)$ & Thinner $(\mathbf{m l})$ \\
\hline 1 (control) & 175 & 0 & 15 \\
2 & 175 & 10 & 15 \\
3 & 175 & 20 & 15 \\
\hline
\end{tabular}

\subsection{Corrosion test}

Beakers containing specific amount seawater were prepared. Coated substrates of different type of coating are ensured to fully dry before the immersion began. SS316L were suspended under the water without touching the base of the beakers. The test was conducted for a period of 30 days at room temperature and stored in safe place to avoid any interruption which may affect the results.

\section{Results and Discussion}

\subsection{Functional group of Kalmegh extract}

Figure 1 shows a considerable amount of functional groups were detected in Kalmegh leaves extract. Several of these functional groups served as a baseline to determine the presence of andrographolide in the extract. Among the discernible components is an asymmetry $-\mathrm{OH}$ at $3361.00 \mathrm{~cm}^{-1}$, an asymmetry $-\mathrm{CH}$ at $2910.25 \mathrm{~cm}^{-1}$ and $2850.50 \mathrm{~cm}^{-1}$, an asymmetry $\mathrm{C}=\mathrm{C}$ stretch at $1645.10 \mathrm{~cm}^{-1}$, a $\mathrm{NO}_{2}$ group of a nitro compounds at $1539.98 \mathrm{~cm}^{-1}$, the aromatic ring demonstrating a peak at $1400.25 \mathrm{~cm}^{-1}$ and a R-COOH, $\mathrm{R}-\mathrm{O}-\mathrm{R}$ and $-\mathrm{OH}$ group at $1080.11 \mathrm{~cm}^{-1}$. As the major component, it has multiple bonds which can be assumed to be able to aid the adsorption process of the coating onto the stainless steel surface. The assumption is due to the action of heteroatom when exposed to an aggressive environment will be protonated thus inducing the reaction between compounds of the extract with the substrate [30]. Moreover, in order to achieve the noble state of orbit, the phenolic group of andrographolide would donate electrons to the metal. This will inherently retard the redox reaction from occurring and thus inhibit the metal from further corrosion process [31]. Table 2 shows functional groups with the corresponding wavenumbers.

\subsection{Absorption spectrum of Kalmegh leaves extract}

$\mathrm{UV}-\mathrm{Vis}$ test is used to measure the amount of light absorbed at a particular wavelength as the light passes through a sample or substances (transparency) in the range of 200-800 nm where the residue was both scanned for absorption maxima. Figure 2 shows the result obtained in which two noticeable peaks were both identified at the adsorption band of $450 \mathrm{~nm}$ and $661 \mathrm{~nm}$. Both of these band fall on the region of visible spectrum with $n-\pi^{*}$ 
electron transition. The wavelength peak at $450 \mathrm{~nm}$ can also represent the $\mathrm{NO}_{2}$ of a nitro compound which symmetrically agrees with the finding by FTIR.

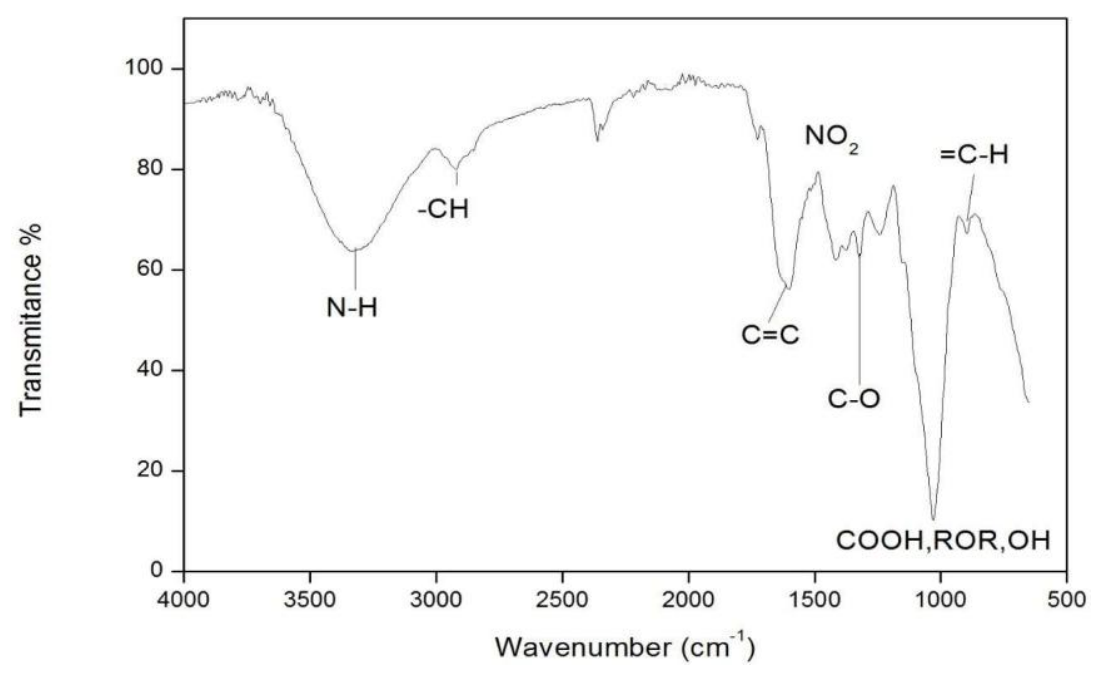

Figure 1. FTIR spectrum of Kalmegh leaves extract

Table 2. FTIR result of Kalmegh extract.

\begin{tabular}{cc}
\hline Wavenumber $\left(\mathbf{c m}^{-\mathbf{1}}\right)$ & Functional group \\
\hline 3361.00 & Carboxylic acid \\
$2910.25,2850.50$ & Alkanes \\
1645.10 & Alkenes \\
1539.98 & Nitro compounds \\
1400.25 & Aromatics \\
1080.11 & Alcohols, carboxylic acids, ester, ether \\
\hline
\end{tabular}

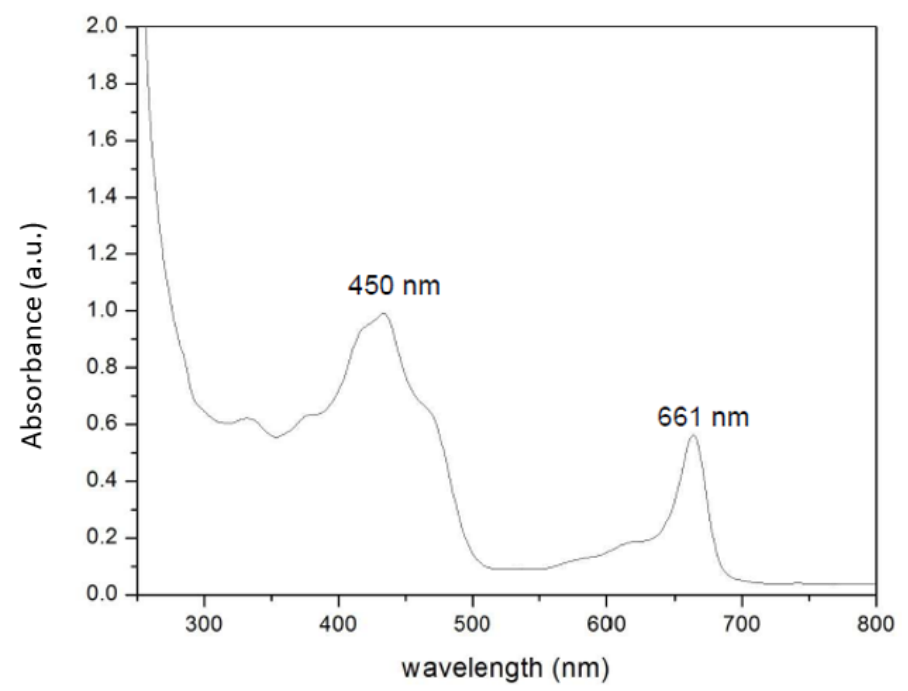

Figure 2. UV-Vis spectrum of Kalmegh leaves extract. 


\subsection{High Performance Liquid Chromatography}

The critical step in the study of HPLC is to devise suitable composition of mobile phases and wavelengths $(\mathrm{nm})$ for the analytical process. The importance of an optimized chromatographic condition is to ensure the peak area of the target analyte appeared best in the chromatogram graph. In the present study, the highest intensity and symmetry of the andrographolide in KLE were observed in wavelength of $225 \mathrm{~nm}$ with composition of water $(20 \%)$ and acetonitrile $(80 \%)$ as mobile phases. The peak area response of target analyte was recorded with $4589710 \mathrm{mV}$ at retention time of $4.650 \mathrm{mins}$ as shown in Figure 3. By comparing the result obtained in the study with a standard of andrographolide of a previous research [32], the shifted in retention time is identified to be mainly due to the different mobile phases used in eluting the analyte. Different solvents have different elution strengths which determine the retention time of analytes in the chromatogram [33]. Thus specificity in the conclusion is ascertained.
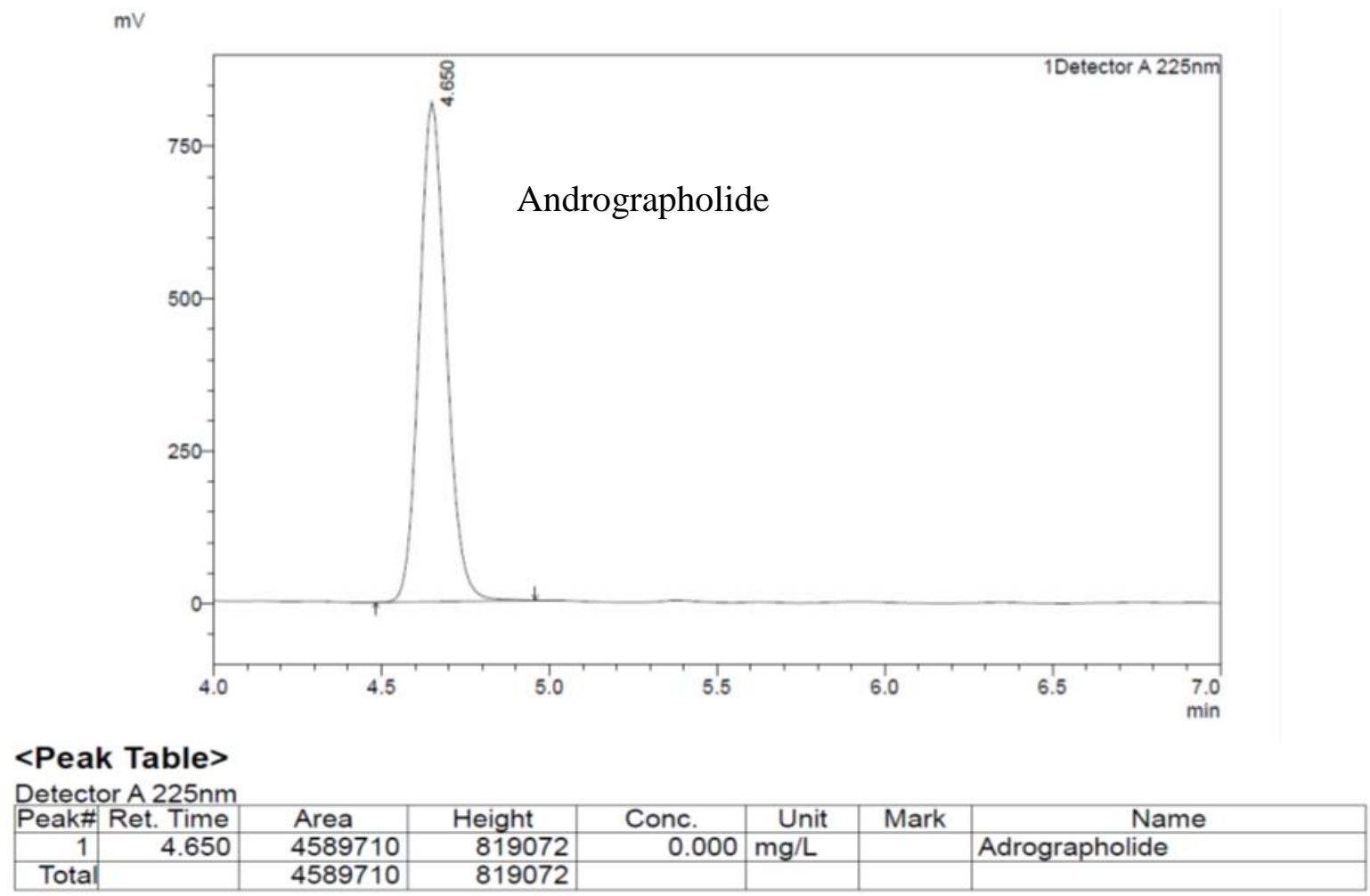

Figure 3. Chromatogram of andrographolide in KLE.

\subsection{Electrochemical Impedance Spectroscopy}

The potential of Kalmegh extract in the inhibition of corrosion was investigated by using electrochemical impedance spectroscopy technique. Through this method, the relationship between extracts concentration and corresponding charge transfer resistance value can be determined. By understanding the electrochemical behavior of the coated sample, an optimization of extract concentration was made. The data were presented in the form of a 
Nyquist plot. Real impedance $\left(Z^{\prime}\right)$ is shown at the $x$-axis while the y-axis represents the imaginary impedance $\left(Z^{\prime}\right)$. From the Nyquist plot in Figure 4, the value of the double-layer capacitance $\left(C_{\mathrm{dl}}\right)$ can be seen to decreases from $1.33 \mu \mathrm{F}$ to $0.85 \mu \mathrm{F}$ from $0 \%$ to $10 \%$ of Kalmegh extract concentration, respectively and the value increased to $1.58 \mu \mathrm{F}$ for $20 \%$ of Kalmegh extract at room temperature. Since the analyzation process was conducted using a simple Randles circuit, the variation of $C_{\mathrm{dl}}$ or can be also termed as the capacitance of coating are usually associated with the amount of water absorb or uptake by the coating [34], where the increase in its value refers to an increase in the dielectric constant value of the coating itself which explicitly occur due to an increasing amount of water absorb. As for the value of charge transfers resistance $\left(R_{\mathrm{ct}}\right)$, it can be observed that an increase in extract concentration yields a further increase of $R_{\mathrm{ct}}$ until a certain limitation was achieved. The value of $R_{\mathrm{ct}}$ increases from $119.73 \mathrm{k} \Omega$ to $186.78 \mathrm{k} \Omega$ at room temperature for the Kalmegh concentration from $0 \%$ to $10 \%$. However, the value of $R_{\mathrm{ct}}$ decreases when the concentration of Kalmegh increases to $20 \%$ with the values of $68.84 \mathrm{k} \Omega$. Increasing $R_{\mathrm{ct}}$ heads to an increment of inhibition efficiency as the value of $R_{\mathrm{ct}}$ is directly related to the response of substrate to corrosion. In fact, $R_{\mathrm{ct}}$ is considered by most researchers to be the major indicator on the efficiency of a coating performance where a lower value of $R_{\mathrm{ct}}$ reflects a poor performance of coating capability in protecting the metal [35].

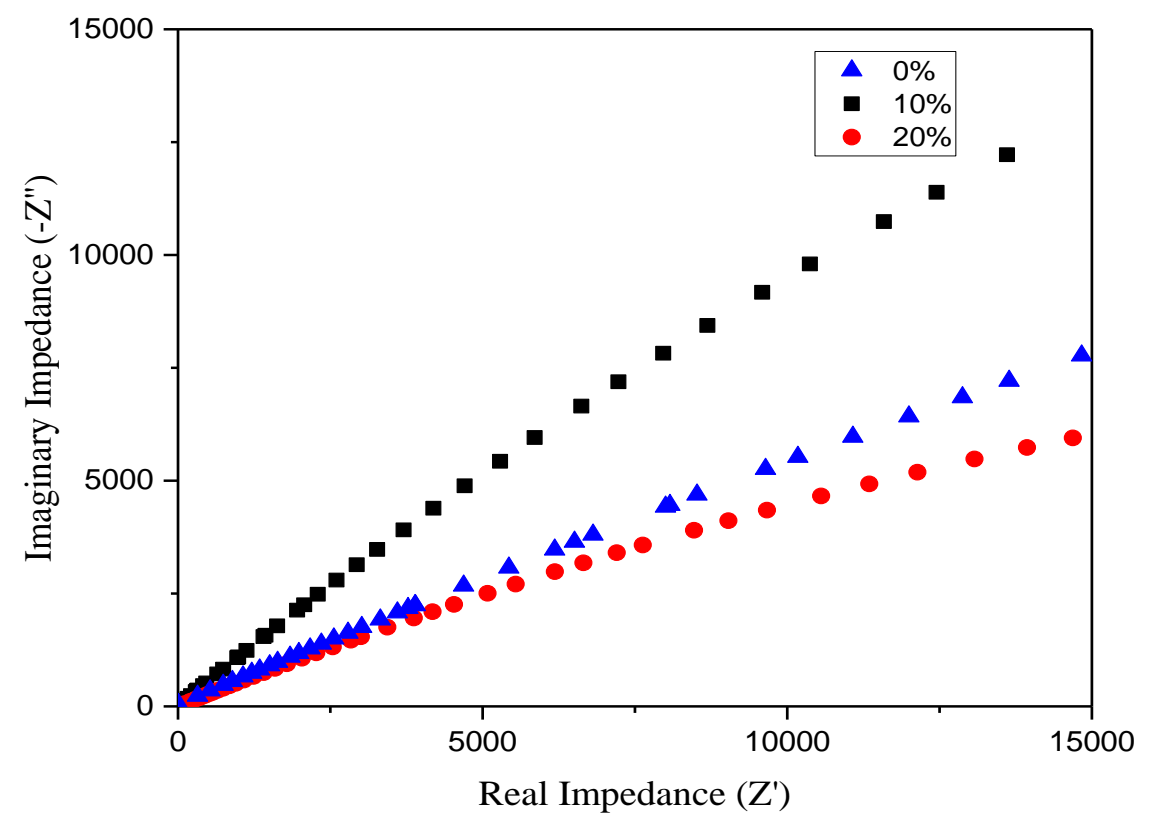

Figure 4. Nyquist graph for 30 days in seawater at room temperature.

From the result, the ratio of Kalmegh extract is limited to $10 \%$ since it causes the $R_{\mathrm{ct}}$ to reduce when the concentration of extract is further increased. Thus, the increasing of Kalmegh extract percentage caused inhomogeneity in the coating sample. The resulting impedance parameters were shown in Table 3. 
Table 3. Impedance parameter of SS316L in seawater for 30 days immersion.

\begin{tabular}{ccc}
\hline Samples & $\boldsymbol{C}_{\boldsymbol{d l}}(\boldsymbol{\mu} \mathbf{F})$ & $\boldsymbol{R}_{\mathbf{c t}}(\mathbf{k} \boldsymbol{\Omega})$ \\
\hline Kalmegh 0\% & 1.33 & 119.73 \\
Kalmegh 10\% & 0.85 & 186.78 \\
Kalmegh 20\% & 1.58 & 68.84 \\
\hline
\end{tabular}

\subsection{Potentiodynamic polarization}

Potentiodynamic polarization is a common method to identify the rate of corrosion or susceptibility of a specific material to corrosion. The results show the Kalmegh extract act as a mixed type inhibitor. The various thermodynamic parameters were calculated and discussed [36]. The polarization measurement was shown in the form of a Tafel plot. Based on Figure 5, the value of corrosion potential $\left(E_{\text {corr }}\right)$ with the presence of Kalmegh extract shifted more to the positive direction. The $E_{\text {corr }}$ value increases when there is an addition of Kalmegh extract which is from $-0.314 \mathrm{~V} / \mathrm{SCE}$ to $-0.281 \mathrm{~V} / \mathrm{SCE}$ for $0 \%$ to $10 \%$; respectively. Although there is increasing value for the $E_{\text {corr }}$ from $0 \%$ to $10 \%$, it was found that the addition of Kalmegh extract up to $20 \%$ decreased it to $-0.290 \mathrm{~V} / \mathrm{SCE}$. The increase of the $E_{\text {corr }}$ value will lower the corrosion rate. As the concentration of Kalmegh extract increases, the $E_{\text {corr }}$ also increases. The increased value of corrosion efficiency is because of the coating layer manages to protect the substrate both physically and chemically from the attack of corrosive species unto the substrates. Previous studies showed that Kalmegh extract affects both the anodic sites and cathodic sites, which is a representation of its mixed-type inhibition characteristic where this can be identify by a significant change in the value of corrosion current density $\left(i_{\text {corr }}\right)$ and the Tafel constant as the extract was added into the coating [20]. Table 4 shows the value of corrosion rate (CR) where the result displayed that $i_{\text {corr }}$ decreased with the addition of Kalmegh extract. Moreover, the addition of $20 \%$ of Kalmegh extract at room temperature was shown to have higher corrosion rate than $10 \%$ of Kalmegh extract. Thus, it can be generalized that Kalmegh extract was found to be limited at $10 \%$ concentration for this study.

Table 4. The electrochemical parameter of SS316L in seawater for 30 days at different Kalmegh concentrations

\begin{tabular}{cccc}
\hline Samples & $\boldsymbol{E}_{\text {corr }}(\mathbf{V})$ & $\boldsymbol{i}_{\text {corr }}(\boldsymbol{\mu A})$ & $\begin{array}{c}\text { Corrosion rate } \\
(\mathbf{m m} / \mathbf{y e a r})\end{array}$ \\
\hline Kalmegh 0\% & -0.314 & 5.85 & 0.06803 \\
Kalmegh 10\% & -0.281 & 1.18 & 0.013753 \\
Kalmegh 20\% & -0.290 & 3.13 & 0.036402 \\
\hline
\end{tabular}




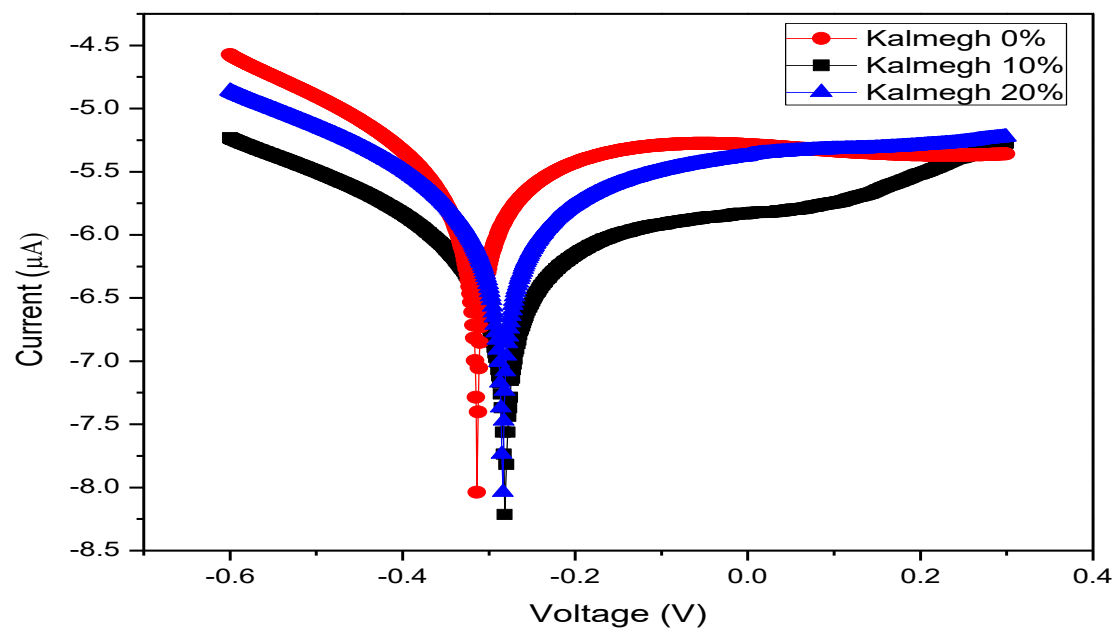

Figure 5. Potentiodynamic polarization curve of SS316L in seawater for 30 days

\subsection{Scanning electron microscope}

Scanning electron microscope revealed information such as surface morphology through the application of focused electron on the sample. SS316L immersed in seawater medium is subjected to the analysis to determine the surface structure of the substrate after the coating application and immersion process. Figure 6 shows the micrographs of SS316L without coating and with coating after 30 days of immersion.
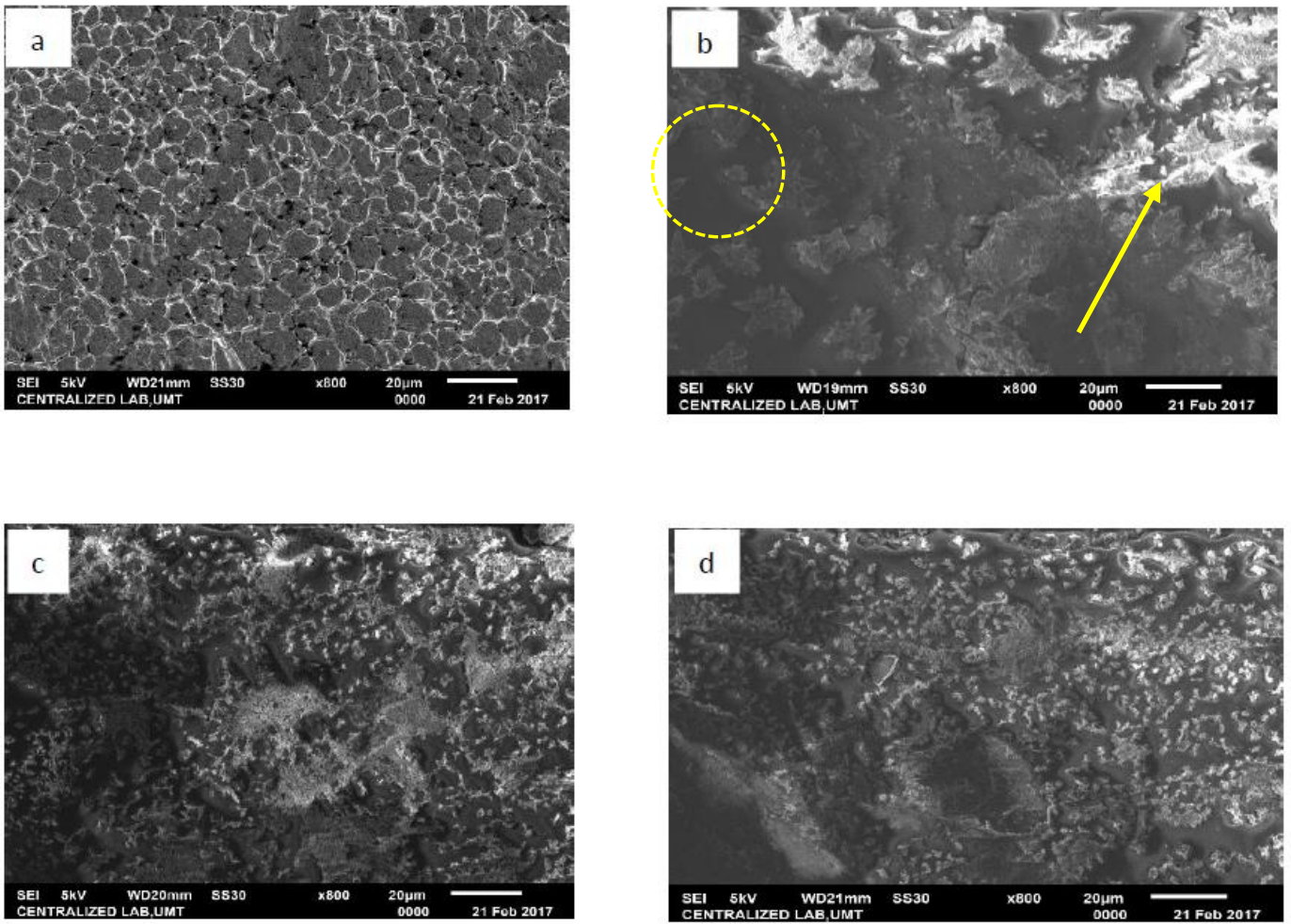

Figure 6. SS316L surface morphology after immersion: (a) without coating (b) with $0 \%$ extract (c) with $10 \%$ extract (d) with $20 \%$ extract. 
Based on Figure 5(a), Figure 5(c) and Figure 5(d), the results show the surface of the substrate was covered with layers of an inhomogeneous coating which portrays significant information on the coating condition after the immersion was conducted. Figure 5(b) shows a lot of craters were formed on the lower part of the images with a distinct mud-like formation on the upper side. Both of the observed craters and white mud-like formation can directly relate to the poor surface preparation of SS316L as shown in Figure 5(a) where the SEM micrograph reveals a rough surface even after the polishing process was done. The situation was due to the use of coarse sandpaper without a proper technique. The presence of white deposition can also be recognized as the salt deposition which generally formed on the surface of coating that has been immersed in chloride-containing solution for an extended period. Furthermore, the condition in Figure 5(b) might also be due to the erosion process which is much more identifiable in both Figures 5(c) and Figure 5(d). For both Figure 5(c) and Figure 5(d), the image shows rough layers on the coating surface where this condition is a sign for an eroded or damaged coating. Additionally, several white spots throughout the surface can also be appointed to the existence of inhomogeneous dispersed of Kalmegh leaves extract or salt deposition. The erosion process which damages the coating surface making it rough is probably due to the aggressive attack of corrosive species in the medium. Other probable causes of the phenomenon are due to the application of the coating was too thick, or coating is flashed too quickly. Layers of the coating may arise in non-regular patterns where paint stresses are uniform. However, the intersection of coating layers can also be linear where brush mark happens in a curved pattern. The problem can be overcome easily by using proper resins and pigments with the addition of material specifically for reducing interior stresses within the coating.

\section{Conclusion}

The use of a natural plant for the inhibition of corrosion is one of the best methods present nowadays. The main constituent that imparts the characteristic of corrosion inhibitor to Kalmegh extract is determined to be andrographolide based on the study of HPLC. Through the analysis of Electrochemical Impedance Spectroscopy, the protection of the surface steel is based upon the coating layer on the metal surface and the formation of passive film. An increase in the concentration of Kalmegh leaves extract within the coating exhibit higher corrosion resistance but limited to $10 \%$ extract concentration only, since further increase will only diminish the efficiency. The analysis on polarization curves also revealed an action of blocking mechanism where the coating reduced the rate of reducing substance such as oxygen from reaching the surface of the steel. To be concluded, Kalmegh possess a good potential as an additive in a marine coating to reduce the progress of corrosion on steel in seawater, and in-depth study on this natural plant in the field should be conducted for a better understanding of its usage and correct method of incorporation. 


\section{Acknowledgments}

The authors gratefully thank the Ministry of Education Malaysia for the financial support through Fundamental Research Grant Scheme (Vot no. 59537). The authors also extend an appreciation for the support of analytical analysis and testing center of Universiti Malaysia Terengganu.

\section{Conflict of Interest}

There are no conflicts of interest to declare by the authors.

\section{References}

1. S.K. Sharma, A. Peter and I.B. Obot, Potential of Azadirachta indica as a green corrosion inhibitor against mild steel, aluminum, and tin: a review, J. Anal. Sci. Technol., 2015, 6, 1-16. doi: https://doi.org/10.1186/s40543-015-0067-0

2. R.M. Palou, O.O. Xomelt and N.V. Likhanova, Environmentally friendly corrosion inhibitors, Developments in Corrosion Protection, Ed. M. Aliofkhazraei, 2014, IntechOpen: Rijeka, HR, p. 432-464. doi: http://dx.doi.org/10.5772/57252

3. M. Finšgar and J. Jackson, Application of corrosion inhibitors for steels in acidic media for the oil and gas industry: a review, Corros. Sci., 2014, 86, 17-41. doi: https://doi.org/10.1016/j.corsci.2014.04.044

4. M. James and D. Hattingh, Case studies in marine concentrated corrosion, Eng. Fail. Anal., 2015, 47, 1-15. doi: https://doi.org/10.1016/j.engfailanal.2014.08.013

5. I. Gurrappa and I.V.S. Yashwanth, The importance of corrosion and the necessity of applying intelligent coatings for its control, Intelligent coatings for corrosion control, A. Tiwari, L. Hihara, and J. Rawlins, Editors. 2015, Butterworth Heinemann: Oxford, UK. p. 17-58. doi: https://doi.org/10.1016/B978-0-12-411467-8.00002-7

6. S.H. Zaferani, M. Sharifi, D. Zaarei and M.R. Shishesaz, Application of eco-friendly products as corrosion inhibitors for metals in acid pickling processes-a review, $J$. Environ. Chem. Eng, 2013, 1, 652-657. doi: https://doi.org/10.1016/j.jece.2013.09.019

7. K. Tebbji, A. Aouniti, A. Attayibat, B. Hammouti, H. Oudda, M. Benkaddour, S. Radi and A. Nahle, Inhibition efficiency of two bipyrazole derivatives on steel corrosion in hydrochloric acid media, Indian J. Chem. Technol., 2011, 18, 244-253.

8. L.T. Popoola, A.S. Grema, G.K. Latinwo, B. Gutti and A.S. Balogun, Corrosion problems during oil and gas production and its mitigation, Int. J. Ind. Chem., 2013, 4, 1-15. doi: https://doi.org/10.1186/2228-5547-4-35

9. A. Kadhim, A.K. Al-Okbi, D.M. Jamil, A. Qussay, A.A. Al-Amiery, T.S. Gaaz, A.a.H. Kadhum, A.B. Mohamad and M.H. Nassir, Experimental and theoretical studies of benzoxazines corrosion inhibitors, Results Phys., 2017, 7, 4013-4019. doi: https://doi.org/10.1016/j.rinp.2017.10.027 
10. S. Martinez and M. Metikoš-Huković, A nonlinear kinetic model introduced for the corrosion inhibitive properties of some organic inhibitors, J. Appl. Electrochem., 2003, 33, 1137-1142. doi: https://doi.org/10.1023/B:JACH.0000003851.82985.5e

11. B. Sanyal, Organic compounds as corrosion inhibitors in different environments - a review, Prog. Org. Coat., 1981, 9, 165-236. doi: https://doi.org/10.1016/00330655(81)80009-X

12. M. Chigondo and F. Chigondo, Recent natural corrosion inhibitors for mild steel: an overview, J. Chem., 2016, 2016, 1-7. doi: http://dx.doi.org/10.1155/2016/6208937

13. S. Durowaye, V. Durowaye and B. Begusa, Corrosion inhibition of mild steel in acidic medium by methyl red (2,4-dimethylamino-2'-carboxylazobenzene), Int. J. Eng. Technol., 2014, 4.

14. M.M. Cowan, Plant products as antimicrobial agents, Clin. Microbiol. Rev., 1999, 12, 564-582.

15. M. Hossain, Z. Urbi, A. Sule and K. Rahman, Andrographis paniculata (Burm. f.) wall. Ex nees: A review of ethnobotany, phytochemistry, and pharmacology, Sci. World J., 2014, 2014, 1-28. doi: https://doi.org/10.1155/2014/274905

16. M.F.F. Maria, W.M.K.W.M. Ikhmal, M.G.M. Sabri and A. Adnan, Identification of functional group present in Andrographis paniculata (Kalmegh) leaves by FTIR analysis, in IOP Conf. Ser. Mater. Sci. Eng. 2018, Terengganu, MY: IOP Publishing. doi: https://doi.org/10.1088/1757-899X/440/1/012035

17. P. Das and A.K. Srivastav, Phytochemical extraction and characterization of the leaves of Andrographis paniculata for its anti-bacterial, anti-oxidant, anti-pyretic and antidiabetic activity, Int. J. Innov. Res. Sci. Eng. Technol, 2014, 3, 15176-15184. doi: https://doi.org/10.15680/IJIRSET.2014.0308016

18. N.P. Trivedi and U. Rawal, Hepatoprotective and antioxidant property of Andrographis paniculata (Nees) in BHC induced liver damage in mice, Indian J. Exp. Biol., 2001, 39, 41-46.

19. V.B. Shalini and J.S. Narayanan, Characterization studies on medicinal plant of Andrographis paniculata (NEES), J. Med. Plants, 2015, 3, 96-102.

20. N. Chaubey, V.K. Singh and M. Quraishi, Electrochemical approach of Kalmegh leaf extract on the corrosion behavior of aluminium alloy in alkaline solution, Int. J. Ind. Chem. , 2017, 8, 75-82. doi: https://doi.org/10.1007/s40090-016-0103-y

21. M. Maria, W. Ikhmal, M. Amirah, S. Manja, S. Syaizwadi, K. Chan, M. Sabri and A. Adnan, Green approach in anti-corrosion coating by using Andrographis paniculata leaves extract as additives of stainless steel 316L in seawater, Int. J. Corros. Scale Inhib., 2019, 8, 644-658. doi: http://dx.doi.org/10.17675/2305-6894-2019-8-313

22. Z.H.Z. Abidin, K.M. Nasir, S.K.M. Jamari, N. Saidon, S.V. Lee, N.A. Halim and R. Yahya, The characteristics of a coating system containing lawsone dye colorant and pmma-acrylic polyol blended resin, Pigm. Resin. Technol., 2013, 42, 128-136. doi: https://doi.org/10.1108/03699421311301124 
23. V.V. Balakrishnan, S. Lee, N. Halim, A. Arof and Z. Abidin, Characterization of poly (vinyl alcohol) coating mixed with anthocyanin dye extracted from Roselle flower with different nitrate salt, Pigm. Resin Technol., 2013, 42, 146-151. doi: https://doi.org/10.1108/03699421311301142

24. W.M.K.W.M. Ikhmal, M.Y.N. Yasmin, M.F.M. Fazira, W.A.W. Rafizah, W.B.W. Nik and M.G.M. Sabri, Anticorrosion coating using Olea sp. leaves extract, in IOP Conf. Ser. Mater. Sci. Eng. 2018. Universiti of Lampung, ID: IOP Publishing. doi: https://doi.org/10.1088/1757-899X/344/1/012028

25. S. Lee, B. Vengadaesvaran, A. Arof and Z. Abidin, Characterisation of poly (acrylamide-co-acrylic acid) mixed with anthocyanin pigment from hibiscus sabdariffa, Pigm. Resin Technol., 2013, 42, 103-110. doi: https://doi.org/10.1108/03699421311301089

26. R. Schiek, Paints and pigments, J. Chem. Educ., 1980, 57, 1-19.

27. A. Kocijan, C. Donik and M. Jenko, Electrochemical and XPS studies of the passive film formed on stainless steels in borate buffer and chloride solutions, Corros. Sci., 2007, 49, 2083-2098. doi: https://doi.org/10.1016/j.corsci.2006.11.001

28. B.D. Craig and L. Smith, Corrosion resistant alloys (CRAs) in the oil and gas industry. 2011, Nickel Institute Technical Series, Toronto, CA. 1-12. doi: https://doi.org/10.1080/1478422X.2017.1384609

29. H.M. Hajar, F. Zulkifli, M.J. Suriani, M.G.M. Sabri and W.B.W. Nik, Lawsonia lnermis extract enhances performance of corrosion protection of coated mild steel in seawater, MATEC Web of Conferences, 2016, Phuket, TH: EDP Sciences. doi: https://doi.org/10.1051/matecconf/20167801091

30. C. Verma, D.K. Verma, E.E. Ebenso and M.A. Quraishi, Sulfur and phosphorus heteroatom-containing compounds as corrosion inhibitors: An overview, Heteroatom Chem., 2018, 29, 1-20. doi: https://doi.org/10.1002/hc.21437.

31. E. Machnikova, K.H. Whitmire and N. Hackerman, Corrosion inhibition of carbon steel in hydrochloric acid by furan derivatives, Electrochim. Acta, 2008, 53, 60246032. doi: https://doi.org/10.1016/j.electacta.2008.03.021

32. M. Rajani, N. Shrivastava and M. Ravishankara, A rapid method for isolation of andrographolide from Andrographis paniculata Nees (Kalmegh), Pharm. Biol., 2000, 38, 204-209. doi: https://doi.org/10.1076/1388-0209(200007)3831-SFT204

33. S.C. Moldoveanu and V. David, Mobile phases and their properties, Essentials in modern HPLC separations, 2012, Newnes, Oxford, UK, 364-419. doi: https://doi.org/10.1016/C2010-0-65748-8

34. C. Moreno, S. Hernández, J. Santana, J. González-Guzmán, R. Souto and S. González, Characterization of water uptake by organic coatings used for the corrosion protection of steel as determined from capacitance measurements, Int. J. Electrochem. Sci., 2012, 7, 8444-8457. 
35. W.M.K.W.M. Ikhmal, M.F.M. Maria, W.A.W. Rafizah, W.N.W.M. Norsani and M.G.M. Sabri, Corrosion inhibition of mild steel in seawater through green approach using Leucaena leucocephala leaves extract, Int. J. Corros. Scale Inhib., 2019, 8, 628643. doi: http://dx.doi.org/10.17675/2305-6894-2019-8-3-12.

36. P. Geethamani and P.K. Kasthuri, Adsorption and corrosion inhibition of mild steel in acidic media by expired pharmaceutical drug, Cogent Chem., 2015, 1, 1-11. doi: https://doi.org/10.1080/23312009.2015.1091558 